\title{
Increasing prevalence of wheeze and asthma in Nottingham primary schoolchildren 1988-1995
}

\author{
A. Venn, S. Lewis, M. Cooper, J. Hill, J. Britton
}

Increasing prevalence of wheeze and asthma in Nottingham primary schoolchildren 19881995. A. Venn, S. Lewis, M. Cooper, J. Hill, J. Britton. CERS Journals Ltd 1998.

ABSTRACT: The prevalence of asthma in children has increased substantially in many countries in recent decades, but it is not clear how much this trend has continued into the 1990s. This study aimed to estimate the current prevalence of asthma and wheeze in British primary schoolchildren and to determine whether there has been any increase in the prevalence of these conditions since 1988.

The prevalence of self-reported wheeze and asthma was measured by parental questionnaire in 22,968 children aged 4-11 yrs attending primary schools in the Nottingham area of England in 1995, and these estimates were compared with data from a subsample of the same schools in 1988.

In 1995, wheezing ever was reported in $24.0 \%$ of children, wheezing in the past year in $15.1 \%$ and diagnosed asthma symptomatic in the past year in $8.8 \%$. All measures have increased in prevalence since 1988, in absolute terms by $7.7 \%$ for wheeze ever, by $2.6 \%$ for wheeze in the past year and by $2.7 \%$ for asthma. The increases were greater in females than males, but did not vary with age.

In conclusion, the prevalence of asthma has continued to rise in British schoolchildren since the late 1980s, particularly in females, and across all ages.

Eur Respir J 1998; 11: 1324-1328.
Division of Respiratory Medicine, University of Nottingham, Nottingham, UK.

Correspondence: A. Venn

Division of Respiratory Medicine

City Hospital, Hucknall Road

Nottingham NG5 1PB

UK

Fax: 441159602140

Keywords: Asthma

children

prevalence

wheeze

Received: September 21997

Accepted after revision February 281998

Funded by the National Asthma Campaign and Dept of Health.
During the last two decades a substantial increase in the prevalence of asthma and wheezing illness has been reported in schoolchildren in the UK [1-8] and in many other developed countries [9-13], and this trend has major implications for public health and service provision. However, it is not certain whether this upward trend has continued since the late 1980s [14]. Recent changes in the prevalence of parent-reported asthma were measured, as well as in the lifetime and 12 month prevalence of wheeze, by comparing data from a study of children aged 411 yrs attending primary schools in the Nottingham area of England in 1995, with values obtained from a similar population in 1988. Prevalence changes by age, sex and school were also assessed to establish the homogeneity of the effects seen.

\section{Methods}

\section{Subjects}

In the summer of 1988 a survey was carried out of the prevalence of wheeze and asthma in all children attending a random sample of three-quarters of the primary schools within a defined postcode area in and around Nottingham [15]. The survey included 13,579 children, aged 4-11 yrs, from 102 schools. In 1995 a further survey was completed covering all children registered in all of the primary schools in the postcode area studied previously. A total of 135 schools was identified, of which 127 participated.
Design

The study was a longitudinal comparison of cross-sectional data from parental questionnaire surveys in 1988 and 1995. The outcome variables were wheeze ever, wheeze in the past year and currently active diagnosed asthma.

\section{Study methods}

Before the 1988 and 1995 surveys, a letter was sent to head teachers explaining the study and requesting consent to proceed. Questionnaires about the child's respiratory health were distributed to all children at the study schools to be taken home for completion by a parent and then returned to the school. Whilst data collection for the 1988 survey involved one questionnaire only, it was necessary in the 1995 study to distribute an initial short questionnaire to all parents in May 1994, and a more detailed parental questionnaire on the child's health and lifestyle, which included the same wheezing questions, in the summer term of 1995. In the original study design it had been intended to distribute this more detailed questionnaire to a selected subsample of cases and controls only, but because of a relatively low response rate to the 1994 questionnaire in some schools, the second questionnaire was distributed to the parents of all children in all schools. Both of these questionnaires were distributed during the summer term for comparability to the 1988 survey. The base population was defined as those children registered in the study schools 
at the time that the second questionnaire was distributed, and therefore responses to the detailed 1995 questionnaire were used for the analysis, if available. However, to improve the response rate, nonresponders to this questionnaire were identified by inspection of the school registers and it was established whether data were available on these children from the previous 1994 questionnaire. If so, this information was included in the calculation of prevalence estimates. Parents of the remaining nonresponders for whom we had no questionnaire data were sent a shortened reminder questionnaire via the school if the child was still attending the school.

The following questions on wheeze were asked on the 1995 detailed and reminder questionnaires.

1) Has your child ever had attacks of wheezing in the chest? (a noisy whistling sound from the chest, not the throat, causing tightness and breathlessness) (yes/no)

2) Has your child had any wheezing attacks in the last year? (yes/no)

3a) Has your child been treated by a doctor for chest trouble in the last year? (yes/no)

3b) If yes, what have you been told is wrong with your child?

Questions 1 and 2 are virtually identical to those appearing on the 1988 and 1994 questionnaires and were used to define lifetime and 12-month prevalence of wheeze, respectively. Currently active diagnosed asthma was defined as a positive response to questions 2 and $3 \mathrm{a}$, followed by a response of "asthma" to $3 \mathrm{~b}$, and this measure of asthma was identical to that obtained from the 1988 questionnaire. However, question 3 differed slightly in structure on the short 1994 questionnaire, and therefore responses on current active asthma from the 1994 questionnaire were not used in the analysis.

The study was approved by the Nottingham Director of Education and Nottingham City Hospital Ethics Committee.

\section{Analysis}

Data were entered into a database using the SPSS data entry programme (SPSS-PC version 4 (SPSS Inc, Chicago, IL, USA)) and analysed by logistic regression using SPSS for Windows (version 7). Differences in prevalence between surveys were calculated, and logistic regression used to construct odds ratios adjusted for age and sex, along with their corresponding $95 \%$ confidence intervals (CI). Age- and sex-specific prevalence estimates of current wheeze for the two surveys were also compared, and odds ratios constructed for 1995 compared to 1988. In schools with Š50 pupils, individual school prevalences and prevalence changes for those schools surveyed in both 1988 and 1995, were calculated and their distributions examined. The correlation between 1988 and 1995 prevalence estimates, and with change in prevalence, was assessed using Spearman's rho.

At the outset of the study, it was estimated that a sample size of 19,500 was needed in 1995 to detect an increase in the 12-month prevalence of wheeze of $1.25 \%$ since 1988 with $95 \%$ statistical power. All analyses have taken a pvalue of $<0.05$ to represent statistical significance.

\section{Results}

Questionnaire data from the current study were obtained for 22,968 children, $83 \%$ of the target population of all children registered in the study schools in June 1995. The majority of these were the detailed questionnaires completed in the summer of 1995 (67\%), with the remainder comprising questionnaires from the preceding stage of the study (21\%) and questionnaires sent out to nonresponders as reminders (11\%). The sample consisted 51\% males, and ranged in age from 4-11 yrs.

A history of wheezing was reported in nearly a quarter of children, wheezing in the past year in $15.1 \%$ and current diagnosed asthma in $8.8 \%$ (table 1). All conditions were significantly more prevalent in males than in females, with age-adjusted odds ratios of 1.41 (95\% CI $1.33-1.50, \mathrm{p}<0.0001)$ for lifetime wheeze, 1.32 (1.23$1.42, \mathrm{p}<0.0001)$ for wheeze in past year and $1.26(1.14$ $1.40, \mathrm{p}<0.0001)$ for asthma. Inspection of the age-specific prevalence estimates revealed that wheezing was most common at the age of 4 yrs and slightly lower prevalences of current whe-eze and asthma were seen in the 7 and $8 \mathrm{yr}$ olds (fig. 1). However, the variation in prevalence between

Table 1. - Period prevalence estimates of wheeze and asthma in 1995 by sex

\begin{tabular}{lccc}
\hline & $\begin{array}{c}\text { Total } \\
\text { responders* }\end{array}$ & $\begin{array}{c}\text { Number with } \\
\text { condition }\end{array}$ & $\begin{array}{c}\text { \% Prevalence } \\
(95 \% \mathrm{CI})\end{array}$ \\
\hline Wheeze ever & & & \\
$\quad$ All & 22,824 & 5487 & $24.0(23.5-24.6)$ \\
$\quad$ Males & 11,543 & 3131 & $27.1(26.3-27.9)$ \\
$\quad$ Females & 11,254 & 2353 & $20.9(20.2-21.7)$ \\
Wheeze in the & & & \\
past year & & & \\
$\quad$ All & 22,863 & 3450 & $15.1(14.6-15.6)$ \\
Males & 11,562 & 1949 & $16.9(16.2-17.5)$ \\
Females & 11,274 & 1500 & $13.3(12.7-13.9)$ \\
Current asthma & & & \\
$\quad$ All & 18,021 & 1584 & $8.8(8.4-9.2)$ \\
Males & 9052 & 879 & $9.7(9.1-10.3)$ \\
Females & 8952 & 705 & $7.9(7.3-8.4)$ \\
\hline
\end{tabular}

*: relates to the total number of responses to that particular question. Note the reduced number of responses to the asthma question due to the omission of data collected during the 1994 stage of this study. $95 \%$ CI: $95 \%$ confidence interval.

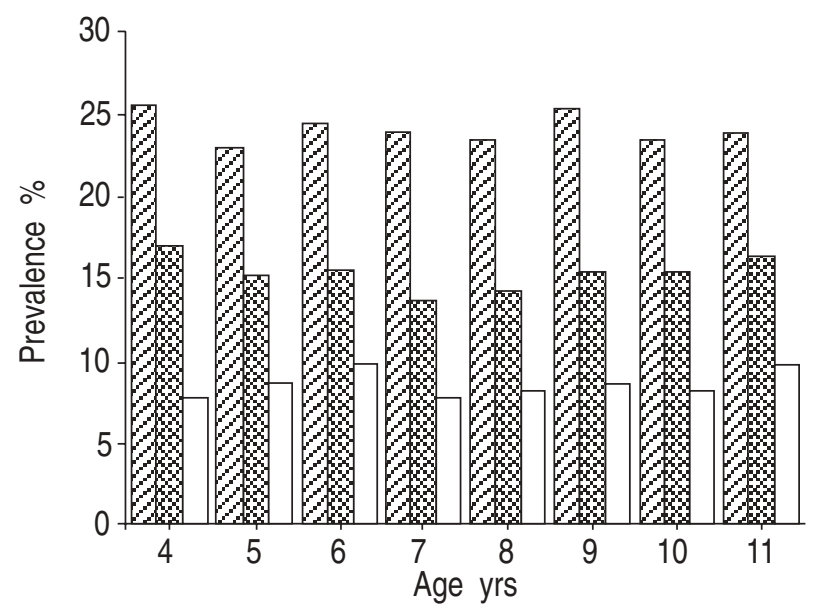

Fig. 1. - Prevalence of wheeze ever ( 2 ), wheeze in the past year ( $\propto$ ) and current diagnosed asthma ( $\square$ ) in 1995 by age. 
ages was not statistically significant and no overall trend with age was seen. Analysis of the distribution of prevalences for the 123 schools with Š50 pupils revealed considerable between-school variation for all conditions $(\mathrm{p}<0.005$ for chi-squared test) with prevalence estimates ranging from $11.6-33.1 \%$ for wheeze ever, $4.8-21.5 \%$ for wheeze in the past year and $1.5-17.9 \%$ for asthma. No clear outliers were identified. Figure 2 shows the observed distribution of prevalence estimates for wheeze in the past year, which is slightly negatively skewed. The distribution of sample prevalences would be expected to be approximately normal, with mean 0.151 and SD 0.027 if school samples were of size 170 (median size of school surveyed). The ex-pected $95 \%$ range $($ mean $\pm 1.96 \mathrm{sD})$ is indicated on figure 2 and 13 prevalence estimates are seen to fall outside this range, more than the six $(5 \%)$ expected by chance. The level of prevalence estimated in individual schools tend- ed to be consistent across the disease outcomes, with a strong correlation seen between the different outcomes (Spearman's rho $=0.76, \mathrm{p}<0.001$ for current wheeze aga-inst asthma). Of the 13 extreme estimates of current whe-eze identified, nine also fell in to the extreme $5 \%$ of the expected distribution of at least one of the other conditions.

Comparing these 1995 estimates with those measured in the 1988 study revealed that both wheezing and asthma had significantly increased in prevalence (table 2). Lifetime wheeze had increased by $47 \%$, representing an absolute increase in prevalence of $7.7 \%$. The 12-month period prevalence of wheeze had also increased over time, from $12.5 \%$ in 1988 to $15.1 \%$ in 1995 , corresponding to an annual increase of $0.4 \%$. A similar sized absolute increase in current diagnosed asthma of $2.7 \%$ was seen between 1988 and 1995. The prevalence of wheezing illness not diag-

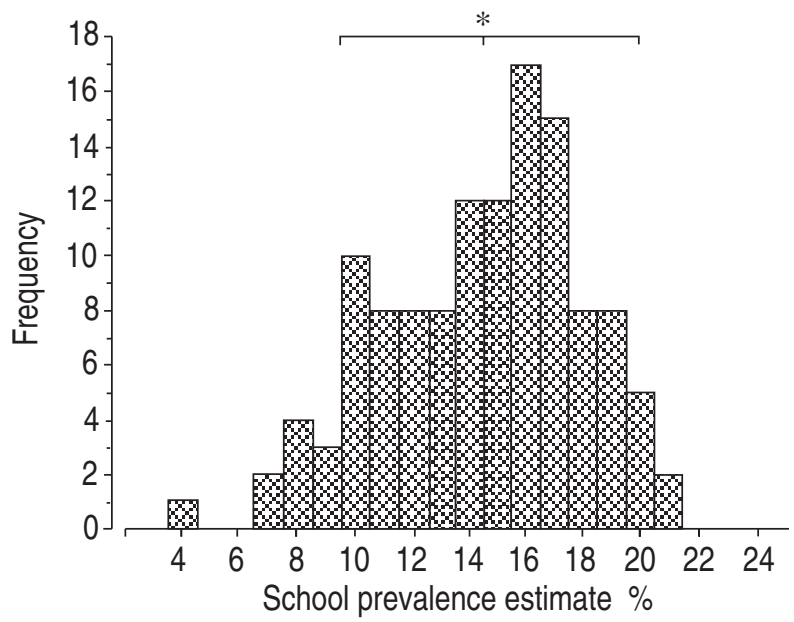

Fig. 2. - Distribution of 1995 school prevalence estimates of wheeze in the past year. *: expected $95 \%$ range $(n=170)$. nosed as asthma remained relatively constant at around 6.3\%. Comparison of prevalence in 1995 and 1988 with adjustment for age and sex by logistic regression resulted in odds ratios of 1.61 for wheeze ever, 1.23 for wheeze in the past year and 1.45 for asthma, all of which were highly significant $(\mathrm{p}<0.0001)$.

Inspection of the sex-specific changes revealed that while significant relative increases were seen for both males and females, these increases were greater in females than males, although only marginally so for lifetime wheeze. The odds ratios for 1995 compared to 1988 for males and females, respectively, were 1.54 (95\% CI 1.43 $1.66)$ and $1.72(1.58-1.87)$ for lifetime wheeze, 1.16 (1.07-1.26) and $1.36(1.23-1.49)$ for current wheeze, and 1.29 (1.16-1.45) and 1.78 (1.55-2.04) for asthma. Fitting a sex-time interaction term into the models confirmed the significance of this effect $(\mathrm{p}=0.05,0.02$ and 0.0006 for wheeze ever, wheeze in the past year and asthma, respectively). Table 3 shows the age-specific prevalence changes for wheeze in the past year for all children, and for males and females separately. Increases were seen across the age groups, with the smallest change in the $4-5 \mathrm{yr}$ old age group, although the overall effect of age on the magnitude of change was not statistically significant (age-time interaction term $\mathrm{p}=0.78$ ); this remained true when males and females were considered separately. Similarly, increases in the prevalence of lifetime wheeze and asthma were seen in all age groups for both males and females, and the size of these increases did not differ significantly with age.

A total of 88 schools surveyed had S50 pupils in both 1988 and 1995, and inspection of the distributions of change in school prevalence for the three outcomes in these schools again showed between-school variation. Not all schools had experienced an increase in prevalence, with 20 schools $(23 \%)$ seeing a fall in the prevalence of diagnosed asthma. The overall range of changes in school prevalence was $-6.4 \%$ to $+16.5 \%$ (mean 7.1 , SD 5.0 ) for wheeze ever, $-7.4 \%$ to $+11.1 \%$ (mean 2.3 , SD 4.1 ) for current wheeze and $-5.2 \%$ to $+9.7 \%$ (mean 2.8 , sD 3.4 ) for asthma. Since a fair amount of sampling variation should be expected with school samples of this size (median 143 in 1988 and 172 in 1995), the observed distribution of prevalence changes was compared with the expected distribution based on samples of median size, and this between-school variation was found to be no more than that expected by chance. Weak but significant positive associations were seen between school prevalence in 1988 and 1995 (Spearman's rho $=0.24,0.31$ and 0.26 for lifetime wheeze, current wheeze and asthma, respectively), although much stronger relations were seen between school prevalence and change in prevalence. A negative correlation between the 1988 prevalence and change in prevalence of current wheeze was observed (Spearman's rho= $-0.56, \mathrm{p}<0.001)$, whereas the relation between the 1995

Table 2. - Comparison of prevalence of wheeze and asthma in 1988 and 1995

\begin{tabular}{lcccc}
\hline & 1988 & 1995 & $\begin{array}{c}\text { Change in } \\
\text { prevalence }\end{array}$ & $\begin{array}{c}\text { Age and sex } \\
\text { adjusted }\end{array}$ \\
& $\%$ & $\%$ & $\%(95 \%$ CI $)$ & OR (95\% CI) \\
\hline Wheeze ever & 16.4 & 24.0 & $+7.7(6.9-8.5)$ & $1.61(1.53-1.71)$ \\
Wheeze in past year & 12.5 & 15.1 & $+2.6(1.9-3.3)$ & $1.23(1.15-1.31)$ \\
Current asthma & 6.1 & 8.8 & $+2.7(2.1-3.3)$ & $1.45(1.33-1.59)$ \\
\hline
\end{tabular}

CI: confidence interval; OR: odds ratio. 
Table 3. - Prevalence of wheeze in the past year in 1988 and 1995 by age and sex, with unadjusted odds ratios for 1995 compared with 1988

\begin{tabular}{|c|c|c|c|c|c|c|c|c|c|}
\hline \multirow[b]{2}{*}{$\begin{array}{l}\text { Age } \\
\text { yrs }\end{array}$} & \multicolumn{3}{|c|}{ All } & \multicolumn{3}{|c|}{ Males } & \multicolumn{3}{|c|}{ Females } \\
\hline & $\overline{1988}$ & 1995 & $\begin{array}{c}\text { OR } \\
(95 \% \mathrm{CI})\end{array}$ & 1988 & 1995 & $\begin{array}{c}\text { OR } \\
(95 \% \mathrm{CI})\end{array}$ & 1988 & 1995 & $\begin{array}{c}\text { OR } \\
(95 \% \mathrm{CI})\end{array}$ \\
\hline $4 / 5^{*}$ & 13.8 & 15.3 & $1.13(0.97-1.32)$ & 16.1 & 18.0 & $1.14(0.94-1.39)$ & 11.3 & 12.7 & $1.15(0.91-1.45)$ \\
\hline 6 & 12.7 & 15.5 & $1.26(1.08-1.46)$ & 15.4 & 16.5 & $(0.88-1$. & 10.1 & 5 & $1.52(1.21-$ \\
\hline 1 & 11.8 & 13.7 & $1.20(1.02-1.40)$ & 13.4 & 15.9 & $1.23(1.00-1.51)$ & 10.0 & 11.5 & $1.17(0.92-1.48)$ \\
\hline 8 & 12.0 & 14.4 & $1.23(1.05-1.43)$ & 14.6 & 16.0 & $1.11(0.91-1.37)$ & 9.6 & 12.8 & $1.38(1.09-1.75)$ \\
\hline 9 & 12.3 & 15.5 & $1.31(1.12-1.53)$ & 14.4 & 16.6 & $1.19(0.96-1.46)$ & 10.3 & 14.3 & $1.45(1.15-1.83)$ \\
\hline $10 / 11^{*}$ & 12.6 & 15.8 & $1.30(1.11-1.53)$ & 15.8 & 17.9 & $1.17(0.94-1.44)$ & 9.7 & 13.7 & $1.48(1.15-1.89)$ \\
\hline Cotal & 12.5 & 15.1 & $1.24(1.17-1.33)$ & 14.9 & 16.9 & $1.16(1.07-1.26)$ & 10.2 & 13.3 & $1.36(1.23-1.49)$ \\
\hline
\end{tabular}

OR: odds ratio; CI: confidence interval. *: the two youngest and the two oldest age groups have been joined together because of the small numbers involved.

prevalence and change in prevalence was positive (Spearman's rho $=0.56, \mathrm{p}<0.001)$. The increases tended to occur in schools with a low to average prevalence in 1988, while schools with an already high prevalence experienced either a fall or little change in prevalence between the surveys. Similar observations were seen for lifetime wheeze and current asthma.

\section{Discussion}

This study has demonstrated a considerable increase in the prevalence of wheeze and asthma in primary schoolchildren since the late 1980s. It is unlikely that these findings could be explained by differences in methodology, since similar methods were adopted for the surveys and only responses to identical questions have been used in the analysis. Since the sample area covered in 1995 was the same as previously, and mostly the same schools were surveyed, differences in population structures should be minimal. Any differences in age or sex structure that were present have been adjusted for in the logistic regression analysis. The possibility was explored that bias might have been introduced by the data being collected over more than one stage for the 1995 survey; for example, the short questionnaire in 1994 may have sensitized responders to the following detailed questionnaire, resulting in higher prevalences. However, this was not seen to be the case, since similar estimates of $23.4 \%$ for lifetime wheeze and $15.4 \%$ for current wheeze were obtained when the data collected from all 18,273 responders in 1994 were analysed alone. Bias arising from nonresponse will be minimal since a high overall response rate was achieved in both studies, $83 \%$ in 1995 and $78 \%$ in 1988 . Therefore valid comparisons can be made between the results.

In interpreting the results, the question arises of whether the increase in asthma prevalence is a genuine one, or is attributable to an increase in the recognition and diagnostic labelling of asthma. The facts that the reporting of wheeze increased in parallel to diagnosed asthma, and the prevalence of current wheeze not diagnosed as asthma has remained constant, suggest that the rise in asthma is real. However, it is possible that parents have continued to become more informed about or aware of respiratory disease and that this has resulted in a further increased tendency to report or recall episodes of wheezing by their child, and increased labelling of these symptoms as asthma by the child's doctor [16]. The magnitude of the increases observed for 12-month period prevalence of both asthma and wheeze are consistent, however, with those reported to have occurred between 1973 and 1988 by BuRR et al. [1], whose serial study of $12 \mathrm{yr}$ old children in South Wales reported an absolute increase in the prevalence of wheeze in the past year of $5.5 \%$ and an increase in current asthma of $5.0 \%$. These figures correspond to increases of $1.8 \%$ and $1.7 \%$, respectively, over 5 yrs, which are remarkably similar to the increases seen in the present study between 1988 and 1995 (1.9\% for both). It can be inferred from this that it is unlikely that all of the observed increases were due to reporting or labelling bias.

This study has revealed that not only current prevalence, but also changes in the prevalence of wheeze and asthma, vary between the sexes. Whilst wheeze and asthma are more prevalent amongst males than females both now and in 1988, females have experienced significantly greater increases, hence narrowing this sex gap. The reasons behind this are unknown. In addition, substantial between-school variability in terms of current prevalence estimates has been identified, and the significance and con-sistency of this heterogeneity across the disease outcomes would suggest that this is not a chance observation. These discrepancies could possibly be attributable to area differences in parental awareness of or education about asthma, which will affect their tendency to report it, or to local differences in exposure to environmental risk factors. However, the pattern of variability in the prevalence change in schools over time, even though no greater than expected by chance, revealed that the rise in prevalence had occurr-ed mainly in schools with a low prevalence of asthma in 1988. This catching-up effect suggests that these regional influences are acting on different schools or areas at different times, and that the schools with a higher prevalence in 1988 may have reached their maximum level. These findings highlight the need to look for potential risk factors on an area basis and not to restrict aetiological inves-tigations to an individual level.

In conclusion, the prevalence of wheeze and asthma has continued to rise amongst primary schoolchildren of all ages since the late 1980 s and the increases are greatest amongst females. Furthermore, the rise in the prevalence of asthma is unlikely to be wholly explained by changes in diagnostic behaviour. This has important implications not only for individuals, but also for schools and health services. These results, and the evidence of marked variation in prevalence between schools, further highlight the need for future investigations into the aetiological factors responsible. 


\begin{abstract}
Acknowledgements: The authors would like to thank P. Housden, J. Swan and T. Dessent, Nottinghamshire County Council for their support of the study, and all the teaching and secretarial staff at the participating schools who made the survey work possible. We also thank M. Antoniak, A. Goldsmith, C. Smith and N. Williamson for their help with data collection.
\end{abstract}

\section{References}

1. Burr ML, Butland BK, King S, Vaughan-Williams E. Changes in asthma prevalence: two surveys 15 years apart. Arch Dis Child 1989; 64: 1452-1456.

2. Ninan T, Russell G. Respiratory symptoms and atopy in Aberdeen schoolchildren: evidence from two surveys 25 years apart. Br Med J 1992; 304: 873-875.

3. Burney PGJ, Chinn S, Rona RJ. Has the prevalence of asthma increased in children? Evidence from the national study of health and growth 1973-86. Br Med J 1990; 300: 1306-1310.

4. Strachan D, Anderson R. Trends in hospital admission rates for asthma in children. Br Med J 1992; 304: 819820.

5. Anderson HR, Butland BK, Strachan DP. Trends in prevalence and severity of childhood asthma. Br Med J 1994; 308: 1600-1604.

6. Rona RJ, Chinn S, Burney PGJ. Trends in the prevalence of asthma in Scottish and English primary schoolchildren 1982-92. Thorax 1995; 50: 992-993.

7. Whincup PH, Cook DG, Strachan DP, Papacosta O. Time trends in respiratory symptoms in childhood over a 24 year period. Arch Dis Child 1993; 68: 729-734.
8. Lewis S, Butland B, Strachan D, et al. Study of the aetiology of wheezing illness at age 16 in two national British birth cohorts. Thorax 1996; 51: 670-676.

9. Peat JK, Van der Berg RH, Green WF, Mellis CM, Leeder SR, Woolcock AJ. Changing prevalence of asthma in Australian children. Br Med J 1994; 308: 1591-1596.

10. Shaw RA, Crane J, O'Donnell TV, Porteous LE, Coleman ED. Increasing asthma prevalence in a rural New Zealand adolescent population: 1975-89. Arch Dis Child 1990; 65: 1319-1323.

11. Robertson CF, Heycock E, Bishop J, Nolan T, Olinsky A, Phelan PD. Prevalence of asthma in Melbourne schoolchildren: changes over 26 years. Br Med J 1991; 302: 11161118.

12. Auerbach I, Springer C, Godfrey S. Total population survey of the frequency and severity of asthma in 17 year old boys in an urban area in Israel. Thorax 1993; 48: 139141.

13. Nystad W, Magnus P, Gulsvik A, Skarpaas IJ, Carlsen $\mathrm{KH}$. Changing prevalence of asthma in schoolchildren: evidence for diagnostic changes in two surveys 13 years apart. Eur Respir J 1997; 10: 1046-1051.

14. Anderson HR. Is asthma really increasing? Paediatr Respir Med 1993; 1: 6-10.

15. Hill RA, Williams J, Tattersfield AE, Britton J. Change in use of asthma as a diagnostic label for wheezing illness in schoolchildren. Br Med J 1989; 299: 898.

16. Magnus P, Jaakkola JJ. Secular trend in the occurrence of asthma among children and young adults: critical appraisal of repeated cross sectional surveys. Br Med J 1997; 314: 1795-1799. 